\title{
“ANIMAL DE LABORATÓRIO"? O CARÁTER EXPERIMENTAL DO TRATAMENTO PARA A ANCILOSTOMÍASE PROPOSTO PELA INTERNATIONAL HEALTH BOARD/FUNDAÇÃO ROCKEFELLER
}

(BRASIL, 1916-1923)

"LABORATORY ANIMAL"? THE EXPERIMENTAL NATURE OF THE TREATMENT FOR HOOKWORM DISEASE PROPOSED BY THE INTERNATIONAL HEALTH BOARD/ROCKEFELLER FOUNDATION (BRAZIL, 1917-1951)

Ana Paula Korndörfer* aninha.korndorfer@gmail.com

RESUMO: Entre 1916 e 1923, onze estados brasileiros e o Distrito Federal contaram com a cooperação da International Health Board da Fundação Rockefeller para combater a ancilostomíase. Milhares de pessoas diagnosticadas com a doença foram tratadas de acordo com o método proposto pela Fundação, o método intensivo, que sofreu modificações no país e foi alvo de críticas. $O$ objetivo deste texto é discutir um aspecto sensível da atuação da Fundação no combate à ancilostomíase no Brasil: a utilização do óleo de quenopódio no tratamento proposto pela instituição norte-americana e, mais precisamente, o aspecto experimental deste tratamento.

PALAVRAS-CHAVE: Fundação Rockefeller, Brasil, ancilostomíase

ABSTRACT: Between 1916 and 1923, eleven Brazilian states and the Federal District relied on the cooperation of the International Health Board of the Rockefeller Foundation to combat hookworm disease. Thousands of people diagnosed with the disease were treated according to the method proposed by the Foundation, the intensive method, which was modified in the country and suffered criticism. The goal of this paper is to discuss a sensitive aspect of the Foundation's activities in the fight against hookworm disease in Brazil: the use of oil of chenopodium in the treatment proposed by the US institution and, more precisely, the experimental aspect of this treatment.

KEYWORDS: Rockefeller Foundation, Brazil, hookworm disease

\section{Considerações iniciais}

\footnotetext{
* Doutora em História pela PUC-RS. Pós-doutoranda PNPD/CAPES - Unisinos
} 
Atualmente, no Brasil, a ancilostomíase ${ }^{1}$, também conhecida no país como amarelão, opilação ou mal da terra, entre outras sinonímias, não figura entre as principais preocupações do governo federal e/ou dos governos estaduais em matéria de saúde pública. No início do século XX, porém, a doença, entendida, naquele contexto, como uma doença "evitável" responsável, em parte, pelo "atraso" do Brasil, foi alvo de ações realizadas a partir de cooperações estabelecidas entre governos estaduais, uma instituição filantrópica norteamericana, a Fundação Rockefeller - FR e, em muitos casos, com a participação também do governo federal.

Entre 1916 e 1923, os estados do Rio de Janeiro, São Paulo, Minas Gerais, Paraná, Maranhão, Rio Grande do Sul, Espírito Santo, Bahia, Santa Catarina, Pernambuco e Alagoas, além do Distrito Federal, contaram com a cooperação da International Health Board $(\mathrm{IHB})^{2}$ da Fundação para combater a doença.

Em linhas bastante gerais, é possível afirmar que, a partir dos acordos de cooperação estabelecidos entre a IHB e os governos estaduais brasileiros, eram realizadas as atividades de combate à ancilostomíase e de saneamento rural, compostas por quatro partes: (a) o survey; (b) a instalação de postos de demonstração do método intensivo de combate à ancilostomíase; (c) a realização de trabalho de educação sanitária, e (d) a melhoria das condições sanitárias, a partir do estabelecimento e da execução de regulamentações que determinassem a instalação de latrinas.

\footnotetext{
${ }^{1} \mathrm{~A}$ ancilostomíase ou ancilostomose é uma verminose adquirida, basicamente, através do contato da pele com o solo contaminado. Entre os sintomas da doença estão anemia, fraqueza e desânimo. O diagnóstico é realizado através da análise das fezes do paciente, pois os ovos dos ancilostomídeos são típicos e costumam ser abundantes na matéria fecal. É possível interromper a transmissão da ancilostomíase da seguinte maneira: (1) através do tratamento de indivíduos parasitados com anti-helmínticos, reduzindo ou suprimindo as fontes de infecção; (2) através de saneamento básico, com o uso de fossas sanitárias e latrinas ligadas a um sistema de esgoto, assegurando assim um destino adequado às fezes humanas e impedindo a contaminação do solo com os ovos e as larvas dos parasitas; (3) com o uso de calçados, protegendo, desta maneira, as pessoas contra a penetração das larvas infectantes (REY, 2001).

${ }^{2}$ A Divisão Internacional de Saúde da Fundação Rockefeller foi criada em 1913 e tinha como objetivo estender o trabalho de combate à ancilostomíase realizado pelos Rockefeller através da Sanitary Commission for the Eradication of Hookworm Disease nos Estados Unidos, desde 1909, para outros países. A Divisão chamou-se International Health Commission (IHC) entre 1913 e 1916, International Health Board (IHB) entre 1916 e 1927 e International Health Division (IHD) entre 1927 e 1951 e, ao encerrar as suas atividades em 1951, havia estado presente em mais de 80 países do mundo, incluindo todos os países da América do Sul. Entre 1913 e 1951, a International Health Division havia atuado no combate à ancilostomíase, à febre amarela e à malária e em outras campanhas de saúde pública no sul dos Estados Unidos e em quase uma centena de outros países ao redor do mundo. Durante o mesmo período, a International Health Division fundou uma série de escolas de saúde pública na América do Norte, Europa, Ásia e Brasil e distribuiu milhares de bolsas de estudos para profissionais da saúde (FARLEY, 2004, p. 2). Neste texto, nos referiremos à Divisão como International Health Board (IHB), nomenclatura que possuía durante as atividades de combate à ancilostomíase realizadas no Brasil.
} 
A primeira atividade da IHB no estado era (a) a realização de um survey para avaliar a distribuição geográfica e a gravidade da ancilostomíase naquela região do país. À exceção do Distrito Federal, levantamentos preliminares foram realizados em todos os estados onde a Fundação atuou em cooperação com os governos.

A partir da análise das amostras de fezes da população examinada, algumas vezes acompanhada do exame do sangue, era possível estabelecer a distribuição geográfica e os índices da doença no estado. De acordo com os surveys, as situações mais graves, no Brasil, eram encontradas nos estados da Bahia, do Maranhão e de Pernambuco.

A partir da realização dos surveys e da identificação dos locais onde a situação da doença era mais grave, (b) postos para a demonstração do método intensivo de combate à ancilostomíase eram instalados. A unidade de atuação da Fundação nos estados era, em princípio, o município. ${ }^{3}$ Durante o período de cooperação entre a Fundação e estados brasileiros para o combate à doença, entre 1916 e 1923, milhares de pessoas diagnosticadas positivamente para ancilostomíase foram tratadas, no país, de acordo com o chamado método intensivo.

Paralelamente ao tratamento da ancilostomíase ocorreria também um trabalho que visava à (c) educação sanitária da população. Este trabalho educacional envolvia palestras, exibições com projeções luminosas e cartazes, visitas de casa em casa para explicações sobre medidas sanitárias e prevenção de doenças, distribuição de literatura e publicação de artigos em jornais.

Os resultados alcançados com o tratamento só poderiam ser garantidos a partir do (d) trabalho de melhoria das condições sanitárias, com a construção de latrinas, e da utilização de calçados.

Meu objetivo, neste texto, é discutir um aspecto sensível da atuação da Fundação no combate à ancilostomíase no Brasil a partir da segunda metade da década de 1910: a utilização do óleo de quenopódio no tratamento proposto pela instituição norte-americana e, mais precisamente, o aspecto experimental deste tratamento. Como afirmei, milhares de pessoas foram tratadas de acordo com o método intensivo no Brasil. O método, que consistia de um ciclo de exames e tratamentos até que a cura do paciente fosse constatada, sofreu modificações no país e foi alvo de críticas. Ao longo dos anos, o tratamento perdeu a característica de buscar a confirmação da cura dos doentes. Já no que se refere às críticas,

\footnotetext{
${ }^{3}$ Hackett to Rose, July 10, 1918 (RAC, RF, RG 1.1, Series 305H, Sub-Series H, Box 15, Folder 134).
} 
estas diziam respeito, principalmente, aos casos de intoxicação relacionados, em especial, à utilização do óleo de quenopódio, principal vermífugo adotado pela Fundação.

A discussão será realizada a partir de periódicos e de documentação produzida pela própria Fundação.

\section{O método intensivo de combate à ancilostomíase e suas alterações no Brasil}

O método intensivo foi elaborado pelo médico G. F. Leonard, a serviço da Sanitary Commission for the Eradication of Hookworm Disease, na ilha de Knott, uma comunidade isolada situada na costa da Carolina do Norte. Durante quase quatro meses, em 1913, o médico buscou livrar a comunidade da ilha de Knott da ancilostomíase e da malária (PALMER, 2010a, p. 67).

Após mensurar a prevalência da ancilostomíase nessa comunidade isolada, o objetivo de Leonard era verificar a possibilidade de eliminar a doença. Em teoria, toda a população de uma pequena ilha poderia ser examinada, tratada e reexaminada para determinar a percentagem de cura (FARLEY, 2004, p. 32).

Dos 567 habitantes da ilha, 560 foram examinados e 93 receberam diagnóstico positivo para a ancilostomíase, sendo tratados com vermífugo - o timol $^{4}$ - repetidas vezes até a constatação da cura. Após três tratamentos, apenas uma das pessoas ainda apresentava resultado positivo para a doença. A partir destes resultados, acreditava-se que a ancilostomíase havia sido praticamente eliminada da ilha e que o método poderia ser utilizado em outros lugares (FARLEY, 2004, p. 32).

Mas as sociedades e os contextos de saúde que os Diretores da International Health Board iriam encontrar nas atividades internacionais da Fundação Rockefeller seriam bastante diferentes dos encontrados na pequena ilha de Knott, cuja população estava concentrada em uma pequena área, apresentava baixos índices da doença e já contava com estrutura médica e sanitária (PALMER, 2010a, p. 67-68). O método intensivo era "poroso",

\footnotetext{
${ }^{4}$ Atualmente, sabe-se que, quando ingerido, o timol $(\mathrm{C} 10 \mathrm{H} 140)$ pode provocar dor abdominal, náusea, vômito, hiperatividade e, ocasionalmente, coma e parada cardiorrespiratória. Óleos e álcool podem promover a sua absorção. O timol pode causar danos ao fígado e aos rins. Informação encontrada em MSDS - Material Safety Data Sheet. Disponível em: http://www.avantmaterials.com/documents/MSDS/usa/English/T3328 msds us Default.pdf. Acesso em: 28 set. 2011.
} 
sendo modificado de acordo com os diferentes contextos que a International Health Boad encontrou nos países em que atuou no combate à ancilostomíase, como veremos no caso do Brasil.

Já no início das atividades da International Health Board no Brasil, em 1917, Lewis Hackett, Diretor Regional da IHB para o país entre 1916 e 1923, apresentava dúvidas quanto à viabilidade da utilização do método intensivo de combate à ancilostomíase no país em sua forma original e que consistia em (1) selecionar uma área, (2) recensear a população da área selecionada, (3) analisar amostras de fezes para averiguar os casos positivos da doença e (4) tratar cada pessoa diagnosticada até que a cura fosse constatada através de exame microscópico. Na interpretação de Hackett, as condições encontradas no Brasil eram desfavoráveis para a aplicação do método, pois, entre outros aspectos, o país apresentava uma população dispersa distribuída sobre um vasto território interligado por estradas em péssimas condições. ${ }^{5}$

Rio Bonito, no estado do Rio de Janeiro, foi a localidade de instalação do primeiro posto de demonstração da Fundação no Brasil. Foi lá também que ocorreu a primeira experiência de aplicação do método intensivo em sua forma original no país. ${ }^{6} \mathrm{~A}$ experiência, segundo Hackett, foi de desapontamento, em razão das dificuldades elencadas acima: longas distâncias e população esparsamente distribuída. ${ }^{7}$ Foi também em Rio Bonito que a primeira modificação do método foi realizada. Após 15 meses de trabalho na localidade, decidiu-se que cada paciente seria objeto de dois exames microscópicos e de três tratamentos, e não seria mais realizado o ciclo de exames e tratamentos até a verificação da cura. ${ }^{8}$ A partir desta modificação, diversas outras são encontradas na documentação produzida pela Fundação com relação ao método de combate à doença no país. As mudanças geralmente estavam relacionadas ao número de exames e tratamentos recebidos por pessoa, mas também ocorreram modificações relacionadas às doses de vermífugo administradas e ao intervalo de tempo entre elas. Além das dificuldades já apontadas para a aplicação do método no país, as péssimas condições sanitárias em que vivia a maioria da população tratada - o que significava a possibilidade de reinfecção - também eram

\footnotetext{
5 No. 7537, Report on Work for the Relief and Control of Hookworm Disease in Brazil from November 22, 1916, to December 31, 1919 (RAC, RF, RG 5, Series 2, Sub-Series 305 Brazil, Box 24, Folder 147).

${ }^{6}$ Report on Work for the Relief and Control of Uncinariasis in Brazil from January 1st to December 31st, 1918 ( RAC, RF, RG 5, Series 3, Sub-Series 305H - Brazil, Box 111, Folder 1434).

7 No. 7537, Report on Work for the Relief and Control of Hookworm Disease in Brazil from November 22, 1916, to December 31, 1919 (RAC, RF, RG 5, Series 2, Sub-Series 305 Brazil, Box 24, Folder 147).

${ }^{8}$ Report on Work for the Relief and Control of Uncinariasis in Brazil from January 1st to December 31st, 1918 (RAC, RF, RG 5, Series 3, Sub-Series 305H - Brazil, Box 111, Folder 1434).
} 
apontadas como motivos para que estas modificações fossem realizadas e para que não se insistisse, assim, na verificação da cura dos pacientes.

Em 1920, o método de combate à ancilostomíase adotado no Brasil passou a consistir em (a) recensear a população; (b) realizar um, e somente um, exame microscópico de todas as pessoas; (c) administrar dois tratamentos-padrão com óleo de quenopódio (1.5 mililitros administrados, pela manhã, em duas doses iguais com intervalo de duas horas, seguidas, depois de outras duas horas, por sulfato de magnésio, um purgante) para os doentes. 0 intervalo entre os tratamentos era de dez dias. Indivíduos com hemoglobina abaixo de $60 \%$ deveriam receber três tratamentos, mas sem exame microscópico adicional. ${ }^{9}$ Todas as pessoas com diagnóstico positivo para qualquer parasita intestinal deveriam receber um tratamento. ${ }^{10}$

Realizado desta maneira, o método de combate à doença, segundo Hackett, poderia ser disponibilizado para os "milhões de infectados" sem demora. De acordo com o médico, estas modificações no método de combate à ancilostomíase possibilitavam que o número de pessoas tratadas em uma localidade fosse duplicado e mantinham praticamente todos os princípios básicos do método intensivo, com exceção de um, o tratamento dos doentes até a verificação da cura. ${ }^{11}$

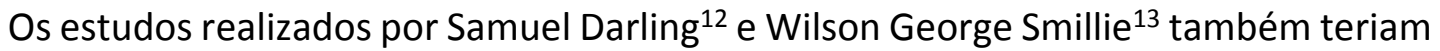
influenciado, segundo relatório de Hackett, as modificações do método de combate à doença empregado no Brasil. Os estudos realizados durante dois anos (1918-1920) por Darling e Smillie em São Paulo haviam demonstrado que dois tratamentos com óleo de quenopódio eliminavam aproximadamente $95 \%$ dos ancilóstomos de um indivíduo e que, portanto, outras doses de medicação para eliminar os ancilóstomos restantes pareciam desaconselháveis. Além disso, os estudos também demonstraram que o exame microscópico falhava em $50 \%$ dos casos leves de ancilostomíase, o que tornava pouco razoável buscar determinar se uma pessoa permanecia infectada depois de dois ou mais

\footnotetext{
${ }^{9} \mathrm{O}$ baixo índice de hemoglobina indicaria a anemia causada por elevado número de vermes.

${ }^{10}$ No. 7597, Report on Work for the Relief and Control of Hookworm Disease in Brazil from November 22, 1916, to December 31, 1920 (RAC, RF, RG 5, Series 3, Sub-Series 305H - Brazil, Box 112, Folder 1438).

11 Idem.

12 Samuel Darling foi o primeiro professor da cadeira de higiene da Faculdade de Medicina de São Paulo e o primeiro diretor (entre os anos de 1918 e 1921) do Instituto de Higiene de São Paulo, instituição que contou com recursos da Fundação. Especialista no combate à ancilostomíase, à febre amarela e à malária, Darling participou ativamente das campanhas de saneamento do Canal do Panamá (FARIA, 2007, p. 104, nota 10).

${ }^{13}$ Wilson George Smillie foi o segundo professor da cadeira de higiene da Faculdade de Medicina e o segundo diretor (entre 1921 e 1922) do Instituto de Higiene de São Paulo. Smillie graduou-se em Harvard e foi especialista na profilaxia da ancilostomíase (FARIA, 2007, p. 104, nota 11).
} 
tratamentos. ${ }^{14}$ Além dos estudos de Darling e Smillie, diversos outros foram realizados no país no período de cooperação entre a Fundação e governos estaduais.

No Relatório Anual de 1922, encontramos outras informações sobre o método de combate à ancilostomíase utilizado no Brasil a partir de 1920. O combate à endemia seria realizado através da seguinte sequência: (a) realização de exame microscópico em comunidades urbanas e em distritos rurais. Quando o índice da infecção atingia 85\%, os exames eram suspensos; (b) nas localidades em que o índice de infecção constatado fosse de $85 \%, 100 \%$ da população era tratada (como se o índice de infecção fosse de $100 \%$ ); (c) eliminação de todos os exames realizados depois do tratamento; (d) prescrição da dosagem e do número de tratamentos de acordo com a idade e a ocupação (exposição à doença), e (e) alta para os pacientes quando fosse completo o número de tratamentos prescritos. $O$ quenopódio era o medicamento utilizado pela Fundação e deveria ser utilizado conforme tabela elaborada e que considerava as idades e a exposição à doença. ${ }^{15}$ Estas modificações caracterizavam o que a Fundação denominaria mass treatment ou tratamento em massa. A primeira aplicação do tratamento em massa no Brasil ocorreu em uma pequena comunidade rural de Santa Catarina no outono de 1920, sendo estendido, depois, a outras regiões do país. ${ }^{16} \mathrm{~A}$ adoção do tratamento em massa, assim como de outras modificações realizadas pela IHB com relação ao número de exames e de tratamentos por pessoa, implicavam não apenas o aumento do número de pessoas tratadas, mas também vantagens econômicas através da diminuição dos custos do tratamento, com a utilização de quantidades menores de vermífugo e a dispensa, por exemplo, dos microscopistas a partir da diminuição ou da suspensão dos exames microscópicos.

Contudo, e isto é importante que se sublinhe, apesar de falarmos aqui das modificações realizadas no método de combate à ancilostomíase empregado pela Fundação no Brasil, os relatórios produzidos pela instituição também indicam que este podia variar de estado para estado e, até mesmo, de município para município, de acordo com as condições locais e a avaliação dos Diretores Estaduais e de Campo. ${ }^{17}$

\footnotetext{
${ }^{14}$ No. 7597, Report on Work for the Relief and Control of Hookworm Disease in Brazil from November 22, 1916, to December 31, 1920 (RAC, RF, RG 5, Series 3, Sub-Series 305H - Brazil, Box 112, Folder 1438). É importante observar que as mudanças no método de tratamento da doença não eram influenciadas apenas por observações e por estudos realizados no Brasil, mas também em outros países onde a Fundação realizava atividades de combate à ancilostomíase.

${ }^{15}$ Annual Report for Brazil, January 1st to December 31st, 1922 (COC/Fiocruz, FR, Doc. 022).

${ }^{16}$ The Rockefeller Foundation Annual Report, 1922, p. 183. Disponível em: <http://www.rockefellerfoundation.org/about-us/annual-reports>.

17 Em termos gerais, o pessoal envolvido nas atividades de combate à ancilostomíase era composto por Diretores Estaduais, Diretores de Campo, microscopistas, enfermeiros (assim referidos na documentação, mas sem formação em enfermagem) e auxiliares (KORNDÖRFER, 2013).
} 
Em um curto espaço de tempo, o método havia passado por uma série de modificações no Brasil e, no início da década de 1920, não incluía mais a verificação da cura dos doentes. Essas modificações, principalmente a partir de 1920, deixavam, segundo Hackett, o método mais seguro. E a segurança do método, ou a falta de, foi justamente o que gerou críticas ao trabalho da International Health Board nas campanhas de combate à ancilostomíase no país. Um dos vermífugos utilizados pela Fundação, o óleo de quenopódio, era apontado como o principal vilão.

\section{A utilização do óleo de quenopódio como vermífugo e as críticas ao trabalho da Fundação no Brasil}

Durante as campanhas contra a ancilostomíase no sul dos Estados Unidos, o timol era o vermífugo adotado pela Fundação Rockefeller. Os riscos envolvidos na sua utilização possuía efeitos colaterais como náusea, vômito, tontura e podia ser, ocasionalmente, fatal - e o seu gosto desagradável fizeram com que pesquisadores da Fundação buscassem um vermífugo mais seguro, palatável e eficiente. No início do século XX, farmacologistas ficaram interessados em vermífugos feitos a partir da planta do quenopódio, conhecida no Brasil como erva-de-santa-maria. O quenopódio já era utilizado eficazmente como medicamento caseiro para tratar verminoses em crianças. A atenção crescente à ancilostomíase ao redor do mundo motivou mais pesquisas na busca de alternativas ao timol, incluindo as pesquisas realizadas por Samuel Darling e Joseph Barber (Ásia, 1914) para a IHB. Antes que os estudos de Darling e Barber estivessem terminados, a I Guerra Mundial interrompeu o suprimento de timol, e a Fundação passou a utilizar o óleo de quenopódio, disponível e mais barato, em suas atividades de campo (PALMER, 2010a, p. 128-129 e PALMER, 2010b, p. 153-154).

Estudos realizados nos Estados Unidos sugeriam que o óleo de quenopódio tinha potencial como vermífugo, mas também já indicavam que a sua utilização poderia trazer riscos. Os diretores da International Health Board aprovaram a utilização experimental do óleo nas campanhas realizadas na América Central e no Caribe britânico. Resultados que variavam de "favoráveis" a "excelentes" foram obtidos na Guatemala, na Costa Rica e na Nicarágua. Mas o uso extensivo do quenopódio, em 1916, levou a relatos de "sintomas alarmantes" e mortes nos Estados Unidos, no Panamá, na Nicarágua, no Ceilão e no Egito. Os diretores da IHB orientaram que o óleo fosse utilizado com cautela até que uma dose e um método de administração seguros fossem estabelecidos (PALMER, 2010a, 129 e PALMER, 2010b, p. 155). Segundo Steven Palmer (2010b, p. 155), "this process of discovery would take place in day-to-day campaigning, using a drug and a methodology that the 
Foundation and the IHB directors understood was not safe, with the children of Latin America, the Caribbean, Asia and the southern United States as experimental subjects".

Entre 1914 e 1934, ano em que a International Health Board deixou de utilizar o óleo de quenopódio, mais de 200 mortes relacionadas ao tratamento com o vermífugo haviam sido registradas e mais de $80 \%$ das vítimas fatais foram crianças com 12 anos de idade ou menos. $^{18}$

No Brasil, a utilização do óleo de quenopódio nas campanhas de combate à ancilostomíase realizadas a partir da cooperação entre a International Health Board e governos estaduais causou intoxicações e deixou vítimas fatais, gerando críticas ao trabalho da Fundação.

Em artigo publicado na Revista Médico-Cirúrgica do Brazil em agosto de 1921, Lewis Hackett, ao realizar uma avaliação dos primeiros cinco anos de atuação da Fundação Rockefeller no Brasil, afirmava que o óleo de quenopódio, único vermífugo utilizado pela International Health Board no país naquele momento, era utilizado não por ser o vermífugo ideal, mas porque apresentava vantagens que compensavam seus inconvenientes. Nas palavras de Hackett, "nenhum outro expelle maior, nem mais variado numero de vermes; nenhum é tão barato ou facil de tomar". ${ }^{19}$

Mas, apesar das vantagens sublinhadas pelo médico, o óleo de quenopódio era "tóxico para certas pessoas" e "por motivos desconhecidos". Segundo dados apresentados por Hackett, a Comissão Rockefeller havia realizado, até 30 de junho de 1921, 644 mil tratamentos no Brasil, e o tratamento empregado parecia ter "causado, ou pelo menos precipitado, a morte de 14 pessoas". Calculada a média da mortalidade - uma morte em cada 46.000 tratamentos - o médico afirmava que esta era menor, por exemplo, do que "os acidentes causados pela anestesia geral". ${ }^{20}$ A grande maioria dos casos de morte ocorria em

\footnotetext{
18 Para chegar a estes números, Steven Palmer analisou documentação da Fundação Rockefeller relativa às campanhas contra a ancilostomíase, incluindo-se dois arquivos com registros de casos de mortes relacionadas ao tratamento com óleo de quenopódio. Um destes arquivos cobre o período de 1915 a 1934 e documenta 129 mortes em que o óleo de quenopódio foi o único vermífugo utilizado no tratamento. O segundo arquivo, que cobre o período de 1922 a 1933, contém o registro de 69 mortes ocorridas durante o tratamento com a mistura de óleo de quenopódio e tetracloreto de carbono. Segundo Palmer, o número de vítimas fatais apresentado nos relatórios e arquivos da Fundação deve ser visto com reservas, pois mortes podem não ter sido registradas por fatores diversos, como negligência e negação da relação entre o tratamento e óbitos (PALMER, 2010b).

${ }^{19}$ HACKETT, Lewis. Os cinco anos da comissão Rockefeller no Brazil. Revista Médico-Cirúrgica do Brazil, ano XXIX, n. 8, p. 344-346, ago. 1921.

${ }^{20}$ Ibidem, p. 346.
} 
crianças com menos de 10 anos: 13 das 14 mortes indicadas no artigo. ${ }^{21}$ Se houvesse outro vermífugo menos tóxico, mas igualmente eficiente, o óleo de quenopódio seria substituído, mas, segundo Hackett, somente uma combinação de drogas poderia fazê-lo. Ainda em defesa do tratamento empregado pela Fundação no combate à ancilostomíase no Brasil, Hackett afirmou que,

\begin{abstract}
A verdade é que o chenopodio não é droga muito perigosa, mas adquirio uma reputação exaggeradamente má, devido á enorme proporção de seu emprego, sem igual em qualquer outra droga. Muitas centenas de milhares de tratamentos são administrados em uma area limitada, em curto espaço de tempo, e, embora seja excessivamente insignificante o numero de accidentes, elles se repetem com relativa rapidez de maneira a attrahir a attenção publica, não preocupada com os accidentes de outras drogas, em uso quotidiano, e com igual ou maior poder tóxico. ${ }^{22}$
\end{abstract}

Segundo o médico, o óleo de quenopódio não era muito perigoso, mas a sua ampla utilização em áreas limitadas e em curto espaço de tempo acabava por atrair a atenção pública para o "excessivamente insignificante número de acidentes". Ao analisar as 14 mortes ocorridas durante o tratamento com o vermífugo, Hackett afirmava que os "acidentes" pareciam "[...] antes uma idiosincrasia por parte dos intoxicados do que mesmo uma toxidez especial do chenopodio usado". ${ }^{23}$

Alguns meses após a publicação do artigo de Lewis Hackett, o jornal O Estado de São Paulo divulgou, em fevereiro de 1922, nota sobre a utilização do óleo de quenopódio no tratamento da ancilostomíase no Brasil. ${ }^{24} \mathrm{~A}$ nota baseava-se numa comunicação, apresentada junto à Sociedade de Medicina e Cirurgia de São Paulo, elaborada por dois médicos, Octavio Gonzaga e Francisco Salles Gomes Junior, como resposta aos argumentos de Hackett acima citados. Segundo os dois médicos, o Brasil, juntamente com outros países como o Panamá, a Costa Rica e a Nicarágua, era campo de experiência dos profissionais norte-americanos no que se referia ao quenopódio. Sublinhavam também que "os acidentes mortais" não eram assinalados nos Estados Unidos, mas eram constatados em todos os outros países onde a Fundação atuava. Segundo Gonzaga e Salles Gomes Junior,

\footnotetext{
${ }^{21}$ Palmer afirma, ao comentar esta mesma avaliação de Hackett sobre a utilização do óleo de quenopódio no Brasil e o cálculo da mortalidade em relação ao número de tratamentos, que, se Hackett tivesse apresentado o cálculo da relação entre crianças tratadas e crianças mortas em decorrência do tratamento, os números seriam bem menos favoráveis (PALMER, 2010b, p.157-158).

22 HACKETT, 1921, p. 346.

23 Ibidem, p. 346.

${ }^{24}$ Emprego do oleo de chenopodio. O Estado de São Paulo, São Paulo, 3 de fevereiro de 1922 (RAC, RF, RG 5, Series 2, Sub-series 305 - Brazil, Box 24, Folder 144).
} 
profissionais de outros países também apontavam os perigos da utilização do óleo, e havia discordâncias entre os próprios profissionais da Fundação Rockefeller no que se referia ao método de administração do quenopódio e à dosagem adequada para as crianças, as principais vítimas dos "acidentes mortais". Os dois médicos entendiam que Hackett não explicara satisfatoriamente as causas das mortes relacionadas ao tratamento com o vermífugo. Não havia justificativa que explicasse a utilização de tratamento tão perigoso em terras nacionais. Para os médicos Octavio Gonzaga e Salles Gomes Junior, segundo a nota publicada,

O oleo de chenopodio seria o vermifugo ideal, se os seus defensores sanassem os seus perigos nas doses aproveitaveis; por emquanto, nada justifica o seu emprego aos azares das campanhas do saneamento, occasionando tantas victimas sem que até hoje o problema fosse resolvido. $^{25}$

Ao concluírem, os médicos teceram fortes considerações recorrendo a nomes de destaque da ciência nacional e mencionando, inclusive, um famoso personagem de Monteiro Lobato. Gonzaga e Salles Gomes Junior acreditavam, de acordo com o texto publicado, que

[...] S. Paulo que, no terreno das experiencias scientificas, viu os bellos exemplos de [Emílio] Ribas e [Adolpho] Lutz submettendo-se ás provas com risco da propria vida, tem o direito de estranhar essa experimentação a frio no nosso "Géca", reduzido á suprema humilhação de animal de laboratório. ${ }^{26}$

Se houve resposta por parte de Lewis Hackett às considerações de Gonzaga e Salles Gomes Junior, não foi possível localizá-la. Contudo, o óleo de quenopódio foi utilizado pela International Health Board no combate à ancilostomíase no Brasil até 1923, ano em que a Fundação se retirou das atividades de combate à doença em estados brasileiros.

\section{O caráter experimental do tratamento proposto pela IHB/FR}

\footnotetext{
25 Idem.

${ }^{26}$ Idem.
} 
A análise de Steven Palmer sobre a utilização do óleo de quenopódio nas campanhas realizadas pela Fundação e as mortes ocorridas em decorrência do tratamento indica que as considerações dos médicos brasileiros Octavio Gonzaga e Francisco Salles Gomes Junior não eram desprovidas de alguma razão. Segundo Palmer, como o próprio programa de combate à ancilostomíase da IHB era considerado um experimento em aberto, todo tratamento era entendido como envolvendo uma dimensão experimental. Todas as instâncias da International Health Board, desde o diretor em Nova York até os médicos da IHB espalhados por diferentes países, entendiam todo tratamento contra a ancilostomíase como um experimento, o que estava relacionado, em parte, ao fato de que a International Health Board recrutava jovens formados em um sistema de educação médica norte-americano reformado, que enfatizava a prática da medicina orientada para a pesquisa. Contudo, sublinha Palmer (2010b, p. 150 e p. 161-162), as pesquisas e estudos realizados por médicos da própria International Health Board durante as campanhas não se transformavam em um protocolo mais seguro para o tratamento da ancilostomíase.

A partir da análise de relatórios sobre experimentos realizados com o óleo de quenopódio durante campanhas de combate à ancilostomíase na Nicarágua entre 1916 e 1920, Palmer afirma que os supervisores locais tinham permissão e eram até mesmo encorajados a agirem como cientistas de saúde pública com licença para usar a população sob tratamento como sujeitos para testes que objetivavam a melhoria de componenteschave da metodologia e do tratamento. Eles também gozavam de considerável autonomia para elaborar e desenvolver estes experimentos, mesmo que envolvessem sérios riscos, como era o caso dos experimentos com os vermífugos (PALMER, 2010b, p. 162).

Isso não significava, porém, que a Fundação permanecesse passiva diante das mortes relacionadas ao tratamento com quenopódio. Ações como a redução nas doses dos vermífugos administrados indicavam, por exemplo, uma busca por tratamentos mais seguros. Contudo, segundo Palmer, os diretores locais da Fundação Rockefeller não pareciam ter sido instruídos a agir de acordo com as descobertas científicas da International Health Board ou utilizar protocolos definidos para a administração do óleo de quenopódio (PALMER, 2010b, p. 164).

A análise da documentação produzida pela IHB referente às campanhas contra a ancilostomíase realizadas no Brasil vai ao encontro das considerações tecidas por Palmer.

No primeiro relatório dos trabalhos realizados no Brasil de acordo com o método intensivo, de 1917, Hackett afirma que, naquele momento, três vermífugos eram utilizados 
no combate à ancilostomíase no país: o óleo de quenopódio, o timol e o naftol $\mathrm{B}^{27}$. $\mathrm{O}$ vermífugo utilizado variava de uma unidade - município - para a outra, de acordo com as decisões do Diretor Estadual. ${ }^{28}$

Uma grande quantidade de dados sobre a eficiência das três drogas utilizadas estava sendo coletada, mas, segundo o relatório de Hackett, era possível afirmar que a dose adulta considerada segura de quenopódio tinha a mesma eficiência que a dose adulta considerada segura de timol, mas o quenopódio custava a metade do valor pago pelo timol. O naftol B, considerado o vermífugo menos eficiente, substituiu o quenopódio no tratamento de crianças em um município do Rio de Janeiro após uma série de incidentes. Três mortes ocorridas naquele estado foram associadas à utilização do óleo de quenopódio no tratamento contra a ancilostomíase. Depois das mortes, o quenopódio foi substituído pelo timol e pelo naftol B no estado do Rio de Janeiro. Nas outras áreas de atuação da Fundação, a dose adulta do medicamento foi reduzida e o intervalo entre tratamentos foi ampliado. ${ }^{29}$

Em carta enviada à mãe após os acidentes fatais ocorridos no Rio de Janeiro, Hacket explicou os prejuízos que as mortes representavam para as atividades da Fundação: "The work is having its setbacks too. We have had two fatal accidents in Rio Bonito within a month from the medicine we are using. We shall have to change the medicine and regain the confidence of the people and that will take time". ${ }^{30}$ As mortes relacionadas ao uso do quenopódio abalavam a confiança das pessoas no tratamento proposto pela Fundação. Ao mesmo tempo, é possível perceber, pelas considerações de Hackett, a sensibilidade da Fundação à reação da população ao tratamento.

Mas, segundo Hackett, todos os Diretores de Campo tinham opinião fortemente favorável ao uso do óleo de quenopódio, pois ele era melhor aceito pelos pacientes quando administrado em cápsulas de gelatina e parecia ser mais eficiente em proporção à quantidade utilizada. Outro aspecto apontado como uma "imensa vantagem" do óleo de quenopódio em relação ao timol e ao naftol B era o fato de ele expelir também o áscaris, um

\footnotetext{
${ }^{27} \mathrm{O}$ naftol B ( $\left.\mathrm{C} 10 \mathrm{H} 80\right)$ pode causar, quando ingerido, dor abdominal, convulsões, diarreia e vômito. Quando exposto ao naftol B por curto espaço de tempo, o indivíduo pode apresentar irritações nos olhos e na pele. A exposição por ingestão pode causar, entre outros, nefrite, colapso circulatório e até mesmo a morte. As informações sobre o naftol B foram encontradas em Material Safety Data Sheet - MSDS. Disponível em: https://fscimage.fishersci.com/msds/97239.htm . Acesso em: 28 set. 2011.

28 No. 7339, Report on Work for the Relief and Control of Uncinariasis in Brazil for the year ending December 31, 1917 (RAC, RF, RG 5, Series 3, Sub-Series 305H - Brazil, Box 111, Folder 1432).

29 Idem.

${ }^{30}$ Hackett to mother, September 1, 1917 (RAC, RF, RG - Special Collection - Lewis Hackett, Series 1.3 Correspondence, Box 8C, Folder 1917 - Hackett, L.W., Correspondence, Personal, July, 1912 - December, 1919).
} 
verme maior e mais visível do que o ancilóstomo, o que teria um efeito psicológico sobre a população. ${ }^{31} \mathrm{O}$ óleo de quenopódio apresentava, então, duas importantes vantagens com relação ao timol, vermífugo que se equiparava a ele em eficiência: era mais barato e tinha um efeito psicológico, pois expelia vermes maiores (mais visíveis) também. O quenopódio acabou se tornando o vermífugo-padrão no Brasil. ${ }^{32}$

Em 1918, um documento que estabelecia as regras gerais para o trabalho no Brasil também enfocava os cuidados a serem tomados na administração do óleo de quenopódio. O documento estabelecia que os enfermeiros não deveriam administrar tratamentos sem ordem do médico e também não poderiam alterar a dose prescrita por ele. Se o paciente ficasse doente repentinamente ou apresentasse más condições de saúde, o enfermeiro deveria suspender o tratamento e consultar o médico. Os enfermeiros e outros empregados das campanhas não tinham permissão para distribuir qualquer outro medicamento que não o fornecido pelo laboratório. Os enfermeiros também não deveriam aceitar dinheiro pelos serviços prestados e medicamentos distribuídos. ${ }^{33}$

No que se referia especificamente à administração do óleo de quenopódio, o documento estabelecia que o óleo deveria ser administrado em cápsulas de gelatina de tamanho-padrão autorizadas pelo Diretor Estadual. Sob nenhuma circunstância era permitido que enfermeiros medissem a quantidade de óleo de quenopódio a ser dada ao paciente fora do laboratório e sem autorização do médico. Os enfermeiros também deveriam informar aos pacientes, se possível, sua localização nas horas seguintes à administração do quenopódio e não deveriam deixar a área, pois assim poderiam ser localizados e chamados em caso de intoxicação. Se um paciente apresentasse sintomas anormais ou ficasse prostrado depois de receber a medicação, o médico deveria ser chamado com urgência. ${ }^{34} \mathrm{~A}$ existência das regras em si aponta a consciência, por parte da Fundação, acerca dos perigos da utilização do óleo de quenopódio e a preocupação com sua administração.

Em 1922, no Relatório Anual, Lewis Hackett não definia os tratamentos com quenopódio realizados no Brasil como experiências, mas apontava que modificações com

\footnotetext{
${ }^{31}$ Esta vantagem do óleo de quenopódio - a expulsão do áscaris e seus efeitos psicológicos - já havia sido percebida nas campanhas realizadas pela Fundação na Guatemala, na Costa Rica e na Nicarágua (PALMER, 2010b, p. 155).

32 No. 7339, Report on Work for the Relief and Control of Uncinariasis in Brazil for the year ending December 31, 1917 (RAC, RF, RG 5, Series 3, Sub-Series 305H - Brazil, Box 111, Folder 1432).

${ }^{33}$ International Health Board, Rockefeller Foundation, General Regulations for Brazil -4/11/1918, Local Rules and Regulations for Brazil - Part IV (COC/Fiocruz, FR, Doc. 014A).

${ }^{34}$ Idem.
} 
relação às doses distribuídas tornaram, possivelmente, o tratamento mais seguro a partir do final de 1919 e início de 1920, com a redução das doses utilizadas no tratamento de adultos e crianças. Ainda segundo o relatório, os anos iniciais foram importantes para o treinamento de médicos e enfermeiros: "These first three years of work [referindo-se ao período entre o final de 1916 e 1919] were of great value to the Doctors and nurses in familiarizing them with the clinical signs of chenopodium intoxication and training them in the more or less expert application of the simple methods of treatment" ${ }^{35}$

A análise das mortes relacionadas ao tratamento com quenopódio apresentada em documentação de 1923 indica, por sua vez, um entendimento, por parte da International Health Board, de que o tratamento estava em fase experimental até 1920 e que somente a partir daquele momento houve uma maior compreensão sobre a toxicidade do vermífugo. Segundo a análise apresentada, “[...] during the first three years of the Board's work in Brazil the use of oil of chenopodium was still in the experimental stage while since 1920 it has been employed with a much clearer understanding of its toxicity". ${ }^{36}$

Naquele ano de 1923, o relatório das atividades realizadas no Brasil indicava que o número total de mortes relacionadas ao tratamento, desde 1917, era de 23 . Uma tabela que relacionava o número de mortes ao número de pessoas tratadas e de tratamentos realizados buscava demonstrar a redução da mortalidade a partir de 1920.

TABELA 1 - Quenopódio - Número de mortes em relação ao número de tratamentos (Brasil, 1917-1923)

\begin{tabular}{lccccc}
\hline Período & $\begin{array}{c}\text { Pessoas } \\
\text { Tratadas }\end{array}$ & $\begin{array}{c}\text { Total de } \\
\text { Tratamentos }\end{array}$ & $\begin{array}{c}\text { Número } \\
\text { de } \\
\text { Mortes }\end{array}$ & $\begin{array}{c}\text { Pessoas } \\
\text { Tratadas } \\
\text { por } \\
\text { Morte }\end{array}$ & $\begin{array}{c}\text { Tratamentos por } \\
\text { Morte }\end{array}$ \\
\hline $\begin{array}{l}1917- \\
1919\end{array}$ & 97.024 & 175.809 & 8 & 12.128 & 21.976 \\
$1920-$ & 657.434 & 1.147 .018 & 15 & 43.829 & 76.467 \\
1923 & & & & & \\
\hline
\end{tabular}

Fonte: Tabela elaborada a partir de dados disponíveis em Progress Reports [1923] (COC/Fiocruz, FR, Doc. 037).

Contudo, um ano após o encerramento da considerada "fase experimental", em 1921, das sete mortes registradas como relacionadas ao tratamento administrado pela International Health Board, seis eram de crianças que morreram horas depois de terem

\footnotetext{
35 Annual Report for Brazil, January 1st to December 31st, 1922 (COC/Fiocruz, FR, Doc. 022).

${ }^{36}$ Progress Reports [1923] (COC/Fiocruz, FR, Doc. 037).
} 
recebido doses de óleo de quenopódio: cinco meninos (um de cinco anos, três de sete anos e um de 13 anos) e uma menina (de oito anos). Quatro destas seis crianças foram apresentadas, no relatório, como possuindo problemas de saúde prévios ao tratamento. ${ }^{37}$

Em 1922, três crianças morreram depois de receberem tratamento com óleo de quenopódio: um menino de oito anos e duas meninas, uma com cinco anos de idade e outra com quatro. A análise apresentada sobre estas mortes não discutia, porém, as questões relativas à toxicidade do quenopódio e destacava que as três crianças possuíam saúde frágil antes mesmo do tratamento. Segundo as informações apresentadas sobre o histórico médico do menino de oito anos, por exemplo, o relatório aponta que "[...] he had always been frail, suffering from frequent attacks of vertigo and convulsions. He was rachitic and anemic". ${ }^{38}$

Chamamos a atenção para a morte da menina de quatro anos de idade, pois Darling e Smillie também haviam realizado estudos sobre a utilização do óleo de quenopódio no tratamento da ancilostomíase em crianças. Em publicação de 1921, os dois afirmavam que o óleo nunca deveria ser utilizado em crianças com menos de cinco anos de idade. Em crianças entre cinco e oito anos, as doses do medicamento deveriam ser pequenas. A morte de crianças com menos de cinco anos em decorrência da administração do óleo de quenopódio no Brasil em 1922 parece confirmar a desconexão, apontada por Palmer (2010b, p. 161-162), entre as pesquisas da própria IHB e o trabalho de campo.

Em 1923, três outras mortes ocorreram após o tratamento com o vermífugo: um menino de 14 anos, uma menina de seis anos e um homem de 56 anos. Com relação às mortes das crianças, novamente foi destacada a saúde debilitada das mesmas, afirmandose que a atribuição das mortes à intoxicação com quenopódio poderia ser, até mesmo, injusta:

In as much as the two children who received chenopodium alone were gravely anemic when treated and one was practically in a moribund condition, it is perhaps unfair to attribute these deaths to chenopodium poisoning. Hookworm disease itself was leading towards the same end. ${ }^{39}$

Esta interpretação defensiva com relação aos casos de intoxicação também é percebida por outros autores. Em seus estudos sobre as campanhas contra a ancilostomíase

\footnotetext{
${ }^{37}$ Annual Report for Brazil, January 1st to December 31st, 1921 (RAC, RF , RG 5, Series 3, Sub-series 305H Brazil, Box 112, Folder 1440).

${ }^{38}$ Annual Report for Brazil, January 1st to December 31st, 1922 (COC/Fiocruz, FR, Doc. 022).

39 Progress Reports [1923] (COC/Fiocruz, FR, Doc. 037).
} 
realizadas pela International Health Board, Steven Palmer (2010b, p. 157)) e AnneEmanuelle Birn (2006, p. 87-88) apontaram que as más condições de saúde das crianças eram frequentemente mencionadas pelos diretores da Fundação como determinantes para as mortes que ocorriam após a administração de doses de óleo de quenopódio. ${ }^{40}$

O relatório de 1923 trouxe ainda informações sobre a experimentação de um novo tratamento para a ancilostomíase: a mistura do óleo de quenopódio com tetracloreto de carbono ${ }^{41}$. Segundo o relatório, em uma série de tratamentos, a mistura de tetracloreto de carbono e óleo de quenopódio havia sido administrada na proporção de 3 para 2 e de 2 para 1, respectivamente. Os resultados dos tratamentos haviam sido bastante satisfatórios, e a mistura se mostrava mais eficiente do que o tratamento realizado somente com o óleo de quenopódio. O mesmo relatório apontava, porém, que o tetracloreto de carbono havia se mostrado tóxico em estudos realizados com cães. Independentemente da dose administrada ou da condição nutricional apresentada pelo animal, o tetracloreto produzia danos ao fígado e aos rins. Em 1923, a morte de um homem de 39 anos, ocorrida no Rio Grande do Sul, foi atribuída à mistura de óleo de quenopódio e tetracloreto de carbono ${ }^{42} .{ }^{43}$

Como podemos observar, o método de combate à ancilostomíase proposto pela Fundação Rockefeller sofreu modificações no Brasil, ao longo do período analisado, como resposta às condições encontradas no país e em virtude de estudos e observações realizados durante as atividades desenvolvidas. Além disso, as fontes também indicam que o método podia variar de estado para estado e, inclusive, de município para município. Ao longo dos

\footnotetext{
${ }^{40}$ Além das más condições de saúde das crianças submetidas aos tratamentos com óleo de quenopódio, Palmer (2010b) e Birn (2006) afirmam também que questões como a má qualidade do vermífugo e a incompetência do pessoal local também eram comumente apontados pelos diretores da IHB como causa das mortes das crianças.

${ }^{41} \mathrm{~A}$ ingestão de tetracloreto de carbono $(\mathrm{CCl} 4)$ pode causar tontura, dor de cabeça, náusea, dor abdominal e diarreia. Em exposições de curta duração, é irritante aos olhos e pode causar danos ao fígado, aos rins e ao sistema nervoso central, podendo ser fatal. Em exposição prolongada, pode ser cancerígeno. Bebidas alcoólicas podem aumentar os efeitos nocivos do tetracloreto de carbono. Estas informações podem ser encontradas em Material Safety Data Sheet - MSDS. Disponível em: https://fscimage.fishersci.com/msds/97239.htm . Acesso em: 28 set. 2011.

42 A mistura de óleo de quenopódio e tetracloreto de carbono foi utilizada pela Fundação Rockefeller na campanha contra a ancilostomíase realizada no México entre 1924 e 1928. Durante os anos da campanha, pelo menos quatro mortes e dúzias de casos de intoxicação foram registrados. A maioria das fatalidades ocorreu com crianças. Segundo Anne-Emanuelle Birn, os relatórios sobre os incidentes relacionados ao tratamento também apresentavam interpretações extremamente defensivas sobre os episódios, que poderiam colocar em dúvida a competência dos funcionários da IHB. A causa dos casos de intoxicação, por exemplo, foi identificada não no tratamento, mas no consumo do pulque, uma bebida alcoólica caseira, e na atuação dos assistentes mexicanos (BIRN, 2006, p. 86-87).

43 Progress Reports [1923] (COC/Fiocruz, FR, Doc. 037).
} 
anos, o tratamento, que inicialmente buscava a confirmação da cura dos doentes, acabou por perder esta característica.

A análise das questões relativas à utilização do óleo de quenopódio e aos óbitos relacionados ao tratamento proposto pela International Health Board apontam o caráter experimental do tratamento no Brasil, modificado à medida que este era administrado à população, confirmando as análises de Steven Palmer sobre a liberdade dos diretores e pesquisadores da Fundação para agirem como cientistas de saúde pública durante as campanhas.

\section{REFERÊNCIAS BLIBLIOGRÁFICAS}

Referências Documentais

Rockefeller Archive Center - RAC

Hackett to Rose, July 10, 1918 (RAC, RF, RG 1.1, Series 305H, Sub-Series H, Box 15, Folder 134).

No. 7537, Report on Work for the Relief and Control of Hookworm Disease in Brazil from November 22, 1916, to December 31, 1919 (RAC, RF, RG 5, Series 2, Sub-Series 305 Brazil, Box 24, Folder 147).

Report on Work for the Relief and Control of Uncinariasis in Brazil from January 1st to December 31st, 1918 ( RAC, RF, RG 5, Series 3, Sub-Series 305H - Brazil, Box 111, Folder 1434).

No. 7597, Report on Work for the Relief and Control of Hookworm Disease in Brazil from November 22, 1916, to December 31, 1920 (RAC, RF, RG 5, Series 3, Sub-Series 305H - Brazil, Box 112, Folder 1438).

Emprego do oleo de chenopodio. O Estado de São Paulo, São Paulo, 3 de fevereiro de 1922 (RAC, RF, RG 5, Series 2, Sub-series 305 - Brazil, Box 24, Folder 144).

No. 7339, Report on Work for the Relief and Control of Uncinariasis in Brazil for the year ending December 31, 1917 (RAC, RF, RG 5, Series 3, Sub-Series 305H - Brazil, Box 111, Folder 1432). 
Hackett to mother, September 1, 1917 (RAC, RF, RG - Special Collection - Lewis Hackett, Series 1.3 - Correspondence, Box 8C, Folder 1917 - Hackett, L.W., Correspondence, Personal, July, 1912 - December, 1919).

Annual Report for Brazil, January 1st to December 31st, 1921 (RAC, RF, RG 5, Series 3, Subseries $305 \mathrm{H}$ - Brazil, Box 112, Folder 1440).

Departamento de Arquivo e Documentação - Casa de Oswaldo Cruz/COC, Fundação Oswaldo Cruz/Fiocruz

Annual Report for Brazil, January 1st to December 31st, 1922 (COC/Fiocruz, FR, Doc. 022).

Progress Reports [1923] (COC/Fiocruz, FR, Doc. 037).

International Health Board, Rockefeller Foundation, General Regulations for Brazil 4/11/1918, Local Rules and Regulations for Brazil - Part IV (COC/Fiocruz, FR, Doc. 014A).

The Rockefeller Foundation

The Rockefeller Foundation Annual Report, 1922, p. 183. Disponível em:<http://www.rockefellerfoundation.org/about-us/annual-reports>.

Biblioteca Nacional

HACKETT, Lewis. Os cinco anos da comissão Rockefeller no Brazil. Revista Médico-Cirúrgica do Brazil, ano XXIX, n. 8, p. 344-346, ago. 1921.

Referências Blibliográficas

BIRN, Anne-Emanuelle. Marriage of convenience: Rockefeller International Health and revolutionary Mexico. Rochester: University of Rochester Press, 2006.

FARIA, Lina. Saúde e Política: a Fundação Rockefeller e seus parceiros em São Paulo. Rio de Janeiro: Editora Fiocruz, 2007. 
FARLEY, John. To cast out disease: a history of the International Health Division of the Rockefeller Foundation (1913-1951). Nova York: Oxford University Press, 2004.

KORNDÖRFER, Ana Paula. "An international problem of serious proportions": a cooperação entre a Fundação Rockefeller e o Governo do Estado do Rio Grande do Sul no combate à ancilostomíase e seus desdobramentos (1919-1929). Tese (Doutorado em História) Faculdade de Filosofia e Ciências Humanas, Pontifícia Universidade Católica do Rio Grande do Sul, Porto Alegre, 2013.

MATERIAL SAFETY DATA SHEET - MSDS. Disponível em: https://fscimage.fishersci.com/msds/97239.htm . Acesso em: 28 set. 2011.

MATERIAL SAFETY DATA SHEET - $\quad$ MSDS. Disponível em: http://www.avantmaterials.com/documents/MSDS/usa/English/T3328_msds_us_Default.pdf. Acesso em: 28 set. 2011.

PALMER, Steven. Launching global health: the Caribbean odyssey of the Rockefeller Foundation. Ann Arbor: The University of Michigan Press, 2010a.

. Toward Responsibility in International Health: Death following Treatment in Rockefeller Hookworm Campaigns, 1914-1934. Medical History, n. 54, p. 149-170, 2010b.

REY, Luís. Um século de experiência no combate da ancilostomíase. Revista da Sociedade Brasileira de Medicina Tropical, Uberaba, v. 34, n. 1, p. 61-67, jan.fev. 2001. 